\title{
LAND USE LAND COVER CHANGES AND THEIR IMPACTS ON ECOSYSTEM SERVICES IN THE NZHELELE RIVER CATCHMENT, SOUTH AFRICA
}

\author{
Nyathi N. $\mathrm{A}^{1 *}$, Zhao $\mathrm{W}^{2}$, Musakwa $\mathrm{W}^{1}$ \\ ${ }^{1}$ Future Earth and Ecosystem Services Research Group Department of Urban and Regional Planning Faculty of Engineering and \\ Built Environment University of Johannesburg Doornfontein Campus Johannesburg, 2028 (nesisan@uj.ac.za) \\ ${ }^{2}$ Institute of Land Surface System and Sustainable Development, Faculty of Geographical Science, Beijing Normal University, \\ No. 19, XinJieKouWai St, HaiDian District, Beijing 100875, China (zhaoww@bnu.edu.cn)
}

KEYWORDS: Land Use Land Cover, Ecosystems Services, Tradeoffs, Policy, InVEST, South Africa

\begin{abstract}
Land use change can result in variations in ecosystem services (ESS) and their relationships. Studying the temporal dynamics of ESS and their relationships can support scenario analyses that provide the theoretical basis for policy decisions and regional ecosystem management in any context. Understanding the spatiotemporal changes in land use and land cover change helps understand ESS management. In this study, the InVEST model was applied to assess carbon sequestration from 1999 to 2018 and to construct two simulated scenarios that represented different land use strategies. The results showed a spatial increase in the cropland class from the stipulated years with a corresponding increase in carbon within the area. It is assumed that the relationship between these two phenomena can affect agricultural policies as a large portion of South Africa depends on it for livelihood betterment. The Spearman's Correlation Coefficient was used to assess the relationship between the two ESS. The result showed a highly significant correlation that means a change in policy from a governmental level is required. This paper subtly aims to provide data towards the South African context and more scenarios and research is needed to fully deduce effective land use management policies and decisions.
\end{abstract}

\section{INTRODUCTION}

The capacity of ecosystems to provide services is determined by many different direct and indirect driving forces operating at the local to global levels (MEA, 2005; Alcamo et al, 2016). Ecosystem services as identified in literature ranges from four types that are namely; provisioning, \{food, fibre and timber\}, (Alcamo et al, 2016), regulating, (carbon sequestration and habitat quality) (Yang et al, 2018), cultural, (aesthetic, music and art), (National Wildlife Federation, 2016) and supporting services (photosynthesis, nutrient cycles) (Chivian et al, 2005). Managing ecosystem services requires the knowledge of the dynamic systems of landscapes and all its changes over time (Hou et al, 2016), as well as its connections to the interactions between services, structures and functions (Chivian et al, 2005). Trade-offs and interactions between different ecosystem services are typical relationships between ESS and their supply and demand, (Yang et al, 2018). Trade-offs can emerge from very complicated social and ecological processes that are difficult to predict (Feng et al, 2013). Trade-offs usually occur when the supply of one ESS decreases because of increased use of another ESS (Yang et al, 2018). Often, tradeoffs involve non-economic and extremely difficult to evaluate values such as cultural identity, employment and the wellbeing of the poor or even an ecosystem structure (Feng et al, 2013). Trade-offs are not always equal, (Feng et al, 2013). A trade-off from one perception may appear as a synergy from another (Kareiva et al, 2007). This is usually the case to conceal or reveal trade-offs based on what ecosystem service outcomes are valued and from whose perspective (Kareiva et al, 2007).

Trade-offs also vary in spatial and temporal scales (Feng et al, 2013), and most commonly, provisioning and regulating services are usually assessed (Yang et al, 2018) resulting in poor land use policies due to the weak aggregate system in measuring the trade-offs between ecosystem services and human wellbeing (Yang et al, 2018; King et al, 2015).

Most studies (Goldstein et al, 2012; Feng et al, 2013; Hirsch et al, 2011), focus on ecosystem trade-offs such as the processes between carbon sequestration and water quality or ecological processes in landscapes, however, little research has been done to calculate the trade-offs between the wellbeing of different human well-being indicators that act as provisioning services and regulating services in a Southern African context. Furthermore, little attention has been paid to the underlying trade-offs between provisional services and regulating services (Feng et al, 2013) as they play a critical role in maintaining ecosystem equilibrium in South Africa. According to (Yang et al, 2018), in agricultural systems, thoughtful management can substantially reduce or eliminate these trade-offs and maximize synergies in ecosystems. The authors (Yang et al, 2018) suggested that the implementation of policy such as the Grain to Green Program implemented in the Loess Plateau in China Mainland can help reduce or weaken trade-offs and enhance synergies, ultimately creating a win-win situation.

The ecosystem service concept has become popular since the United Nations' Millennium Ecosystem Assessment 2005 (further referred to as MEA, 2005). To achieve sustainable ecosystems services (Apitz et al, 2006), an integrative approach can be implemented (Euliss Jr et al, 2011). This approach unifies quantitative studies (Yang et al, 2018; Fu et al, 2013) and allows scenarios to be drawn for effective decision making (Euliss Jr et al, 2011). Careful management of ecosystems within our modern and highly diverse landscapes is important for intergenerational sustainability 
of ecosystems (Euliss Jr et al, 2011). Understanding how land use changes affects multiple and simultaneous ecosystem services helps researchers appreciate processes of regulating them in an integrative manner. The development of cost effective (Euliss Jr et al, 2011), integrated (Fu et al, 2013) and adaptative modelling of ecosystems services for sustainable development helps evaluate and assess ESS and landscape changes on a bigger scale. For example, a study carried out by (Euliss Jr et al, 2011) used a frame-based model approach to quantify ESS derived from landscape changes. The authors focused on the ecologically diverse Lower Mississippi Valley. Furthermore, the model showed that different land uses led to different quantities of ESS in the area and to quantify them using a frame by frame approach was best. This model, (Euliss Jr et al, 2011) shows that with the correct conditions set (economic, policy and management), landowners, policy makers and stakeholders can evaluate the area for ecological trade-offs involved in complex landscapes.

The provision of ecosystem services is directly linked to the condition of ecosystems (Kimmings et al, 2016), e.g. land use/land cover (LULC) types, in a given area (Kimmings et al, 2016; de Groot et al., 2002; Styers et al., 2010). Dynamics of LULC can cause changes in the values of ecosystem services (Kreesta et al., 2016; Hu et al., 2018; Polasky et al., 2011). Cai et al (2016) outlined that one of the fundamental issues that cause land use changes are landscape fragmentation which in changes the structure and pattern of ecosystems, (Yang et al, 2018) and decreases the function of the ecosystems, (Cai et al, 2016). The identification and measurement of varying ecosystem services linked to changing landscapes helps quantify (Yang et al, 2018) the environmental cost-benefit (Cai et al, 2016) and decisions allowing decision makers to better understand different trade-offs (Alcamo et al, 2016) for efficient ecosystems services and land use management. The Integrated Valuation of Ecosystem Services and Tradeoffs (InVEST) model is one such tool that can be used to quantify land use changes and simultaneously spatially estimate ESS quantities (Nelson et al, 2009; Yang et al, 2018). For example, (Yang et al, 2018) used InVest to quantify five regulating ESS for observed land use changes in the Loess Plateau in China.

Generally, regulating services tend to increase and the provisioning services decrease with the input of human wellbeing or needs into the equation (Yang et al, 2018; Sharps et al, 2017; Seppelt et al, 2013). Since the most common tradeoffs in ESS happen between regulating and provisional services. To fully understand landscape restoration and land degradation management (Olver, 2012) conflicts are bound to arise. Having the ability to see across such scenarios (Seppelt et al 2013) gives rise to the possibility of land use change management strategies, inform policy as well as ESS management (Yang et al, 2018). Mapping ESS grounded on multiple land use land cover change scenarios can expose all the changes in ESS given diverse future land use patterns in order to inform land use decisions and planning (O'Farrell and Anderson, 2010; Raudsepphearne et al., 2010; Yang et al, 2018). Most studies (Yang et al, 2018; Nelson et al, 2009; Yao et al, 2019) focus on the different scenarios that are informed by policy in ESS assessment. These studies are useful in assisting policy making and achieving sustainable development (Yao et al, 2019), moreover, quantifying ESS based on scenarios also provides data for future studies seeing as the need for knowledge about ESS management in an African context is big.

Integrated ESS research gives weight to the development of efficient and sustainable ecosystems (Apitz et al., 2006; Yang et al, 2018). Furthermore, using an integrative ESS approach allows policy makers to make informed decisions on food production and consumption (Fu et al., 2013; Yang et al, 2018). The use of models to calculate and predict ESS drivers and impacts as well as tradeoffs in Africa is limited and therefore the need to is observed. Constructing future scenarios of ESS changes and impacts will help with the achievement of the Sustainable Development Goals (SDGs) in South Africa. Due to the policy of separate development (Van Langyelde, 2019) intensive farming is found on the northern side of the Nzhelele Catchment area and communities are found on mountainous regions south of the area. This in turn leads to lack of arable land and service delivery for vulnerable people in the area. Given the limitations of existing ESS dynamics and scenario studies in terms of policy making and food production in South Africa, the study aims to analyze the influence of land use change on ESS trade-offs in the Nzhelele Levhuvhu Catchment area, South Africa. The study specifically aims to (1) map and quantify land cover change in the above mentioned study area from 1999 to 2018, (2) to quantify carbon sequestration and crop production using the carbon model (InVEST) and to (3) assess current trade-offs between provisional and regulating ESS in the study area. The result is expected to provide accurate guidance for land use decision makers to formulate future regional ecological restoration land use policies for both subsistence and commercial farmers.

\section{METHODS AND MATERIALS}

This section provides the study methods and the materials used to achieve results. For efficiency, every objective is addressed along with the results.

\subsection{Study Area}

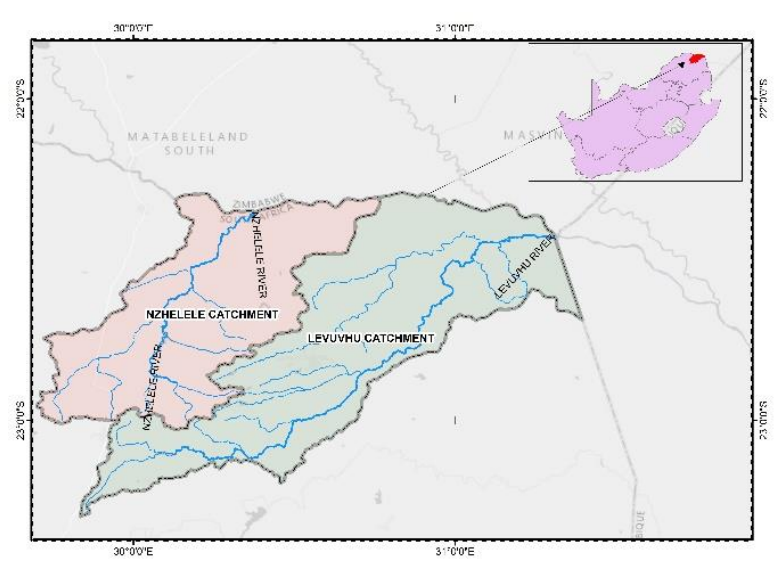

Figure 1: Map showing the location of the study area Source: (Musakwa et al, 2020) 
The 2,436 square kilometers catchment area $\left(22^{\circ} 21^{\prime} 08^{\prime \prime} \mathrm{S}\right.$ $30^{\circ} 22^{\prime} 19^{\prime \prime} \mathrm{E}$ ) is a watercourse area that is found in the Limpopo Province, South Africa (Makungo, 2010). The area has a major river that runs through it, the Nzhelele River. This river collects much of the drainage of the northern slopes of the extensive rock formation of the Soutpansberg (Makungo, 2010). The Mutamba River, its main tributary, rises in the Buelgum Poort farm of the Soutpansberg, further west from the sources of the Nzhelele. The area is a semiarid region that receives a mean annual rainfall of $200 \mathrm{~mm}$ (South African Weather Services SAWS, 2018).

\subsection{Data Sources and Land Cover Mapping Analysis}

Two data types were used in this study: (1) 30-m resolution Landsat maps, which were obtained from the USGS Earth Explorer website (www.earthexplorer.usgs.gov) (2) $30 \mathrm{~m}$ resolution ASTER GDEM V2, Digital Elevation Model (DEM), (www.srtm.usgsearthexplorer.gov), as explained in table 1:

\begin{tabular}{|l|l|l|l|l|l|}
\hline Sensor & DOA & RES & $\begin{array}{l}\text { No of } \\
\text { Bands }\end{array}$ & Source & $\begin{array}{l}\text { Bands } \\
\text { Used }\end{array}$ \\
\hline $\begin{array}{l}\text { Landsat } \\
\text { 8 OLI }\end{array}$ & $\begin{array}{l}25 / 03 \\
/ 2018\end{array}$ & $30 \mathrm{M}$ & 11 & $\begin{array}{l}\text { Earth } \\
\text { Explorer }\end{array}$ & $5,4,3$ \\
\hline $\begin{array}{l}\text { Landsat } \\
5 \mathrm{TM}\end{array}$ & $\begin{array}{l}29 / 03 \\
/ 2008\end{array}$ & $30 \mathrm{M}$ & 8 & $\begin{array}{l}\text { Earth } \\
\text { Explorer }\end{array}$ & $4,3,2$ \\
\hline $\begin{array}{l}\text { Landsat } \\
\text { 5 MSS }\end{array}$ & $16 / 04$ & $30 \mathrm{M}$ & 7 & $\begin{array}{l}\text { Earth } \\
\text { Explorer }\end{array}$ & $4,3,2$ \\
\hline
\end{tabular}

Table 1: Landsat data acquisition

Land use land cover change was quantified using the random forest classification in ArcGIS 10.5. The classification reflected land use at nine-year and ten-year intervals respectively: 1999, 2008 and 2018. The land use land use cover was classified into six land use types namely: water, bare land, vegetation, settlements, grassland and cropland. Due to the difficulty in quantifying cropland at pixel level (Yang et al, 2018), cropland class was used to represent food production. The overall accuracy of the classification was $82 \%$ with a producer accuracy of $84 \%$ and a user accuracy of $81 \%$.

\section{LULC in Hectares}

DArea_ha_2018 DArea_ha_2008 घArea_ha_199

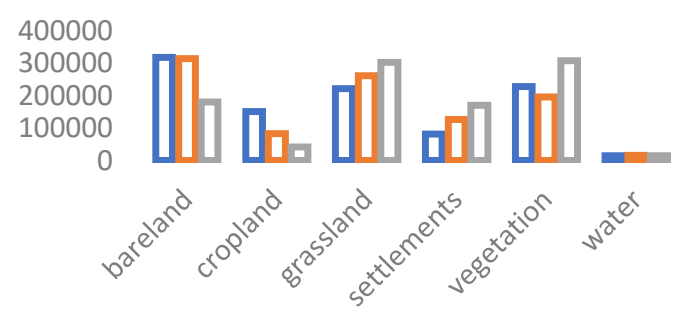

Figure 3: A graph showing the magnitude of areal coverage from land cover maps in (Ha)
Statistics indicating the magnitude of areal coverage of each land cover type for all dates with changes recorded are given in (figure 3). In the year 1999, the vegetation class had the highest cover with 307255 ha of the total area. Grassland occupied 301414ha, croplands occupied 41211 ha of the total surface area. Settlements occupied 169651 ha while water occupied 141125ha. In 2008, bareland class occupied most of the surface area with $313405 \mathrm{ha}$, grassland with 260791ha, cropland with 81966ha and water with 16176ha. In 2018, cropland class occupied the most area with 378441 ha, and bareland was next with 249411 ha, settlements occupied $127692 \mathrm{ha}$ and water at $35135 \mathrm{ha}$.
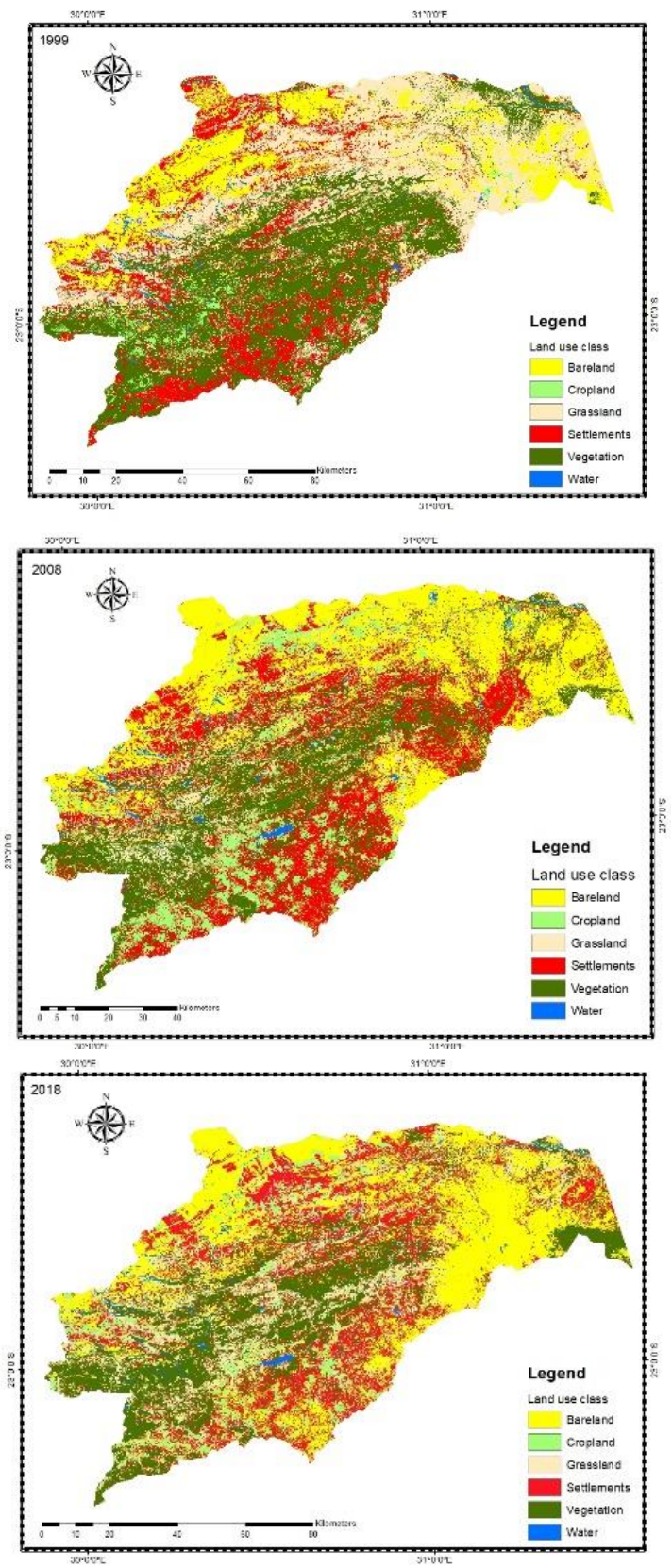

Figure 2: Three maps showing 1999, 2008 and 2018 Random Forest Classification 


\subsection{Quantifying Carbon Sequestration}

The carbon model was used to evaluate carbon sequestration (CS). Carbon storage on a land parcel largely depends on the sizes of four carbon and dead organic matter. The InVEST Carbon Storage and Sequestration model aggregates the amount of carbon stored in these pools according to land use maps and classifications provided by the user (http://releases.naturalcapitalproject.org/invest-

userguide/latest/index.html, Invest: 2018). The land use maps and values for the four carbon sinks noted above were required for this model to run. Most authors (Woomer et al., 2004; Gockowski and Sonwa, 2011; Adu-Bredu et al., 2011; Yao et al., 2010) calculated their carbon using the standardized carbon pool table developed for studies, however, this study developed a study area contextualized pool table (Table 2). The carbon sink data was acquired from the African IPCC carbon stock table, at (http://www.ipcenggip.iges.or.jp/public/2006gl/pdf/4 Volu me4/V4 02 Ch2 Generic.pdf, IPCC 2006).

\begin{tabular}{|l|l|l|l|l|l|}
\hline $\begin{array}{l}\text { LULCc } \\
\text { ode }\end{array}$ & $\begin{array}{l}\text { LULC_nam } \\
\text { e }\end{array}$ & $\begin{array}{l}\text { C_abo } \\
\text { ve }\end{array}$ & $\begin{array}{l}\text { C_bel } \\
\text { ow }\end{array}$ & $\begin{array}{l}\text { C_s } \\
\text { oil }\end{array}$ & $\begin{array}{l}\text { C_de } \\
\text { ad }\end{array}$ \\
\hline $\mathbf{0}$ & Water & 1 & 1 & 10 & 0 \\
\hline $\mathbf{1}$ & Vegetation & 1643 & 1031 & 1096 & 505.5 \\
\hline $\mathbf{2}$ & Grassland & 29 & 23 & 128 & 4 \\
\hline $\mathbf{3}$ & Cropland & 47 & 28 & 218 & 2 \\
\hline $\mathbf{4}$ & Settlements & 22 & 14 & 135 & 1 \\
\hline $\mathbf{5}$ & Bareland & 10 & 20 & 10 & 5 \\
\hline
\end{tabular}

Table 2: Study area contextualized carbon pool table (mg/pixel)

Figure 4 shows maps of the current carbon and future carbon storage in the study area. While the current carbon map refers to the LULC of the year 2018, the future carbon storage map uses the LULC map of 2018 with table 2 as the pool table, the standardized carbon sink table and a projection of 2030 to calculate the future carbon storage. The range of the carbon stored in the study area currently is from 1.06 to $384 \mathrm{mg}$ per pixel.

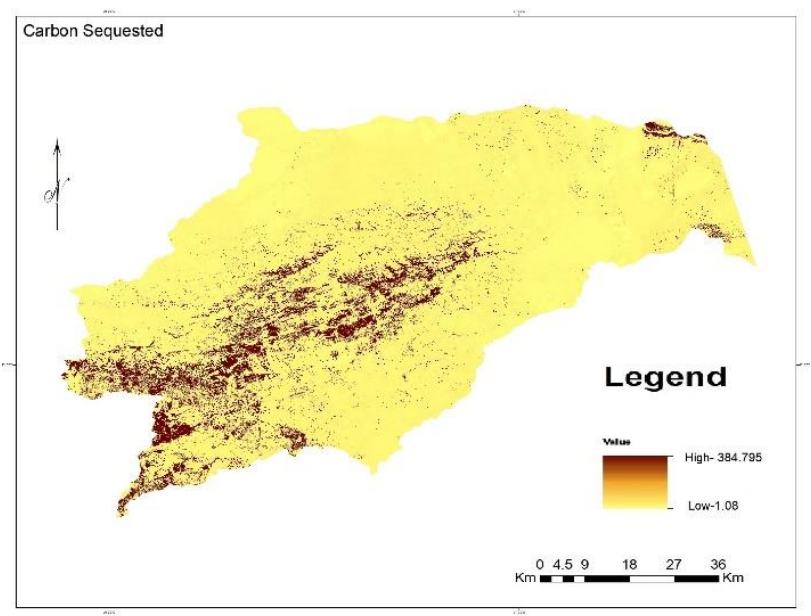

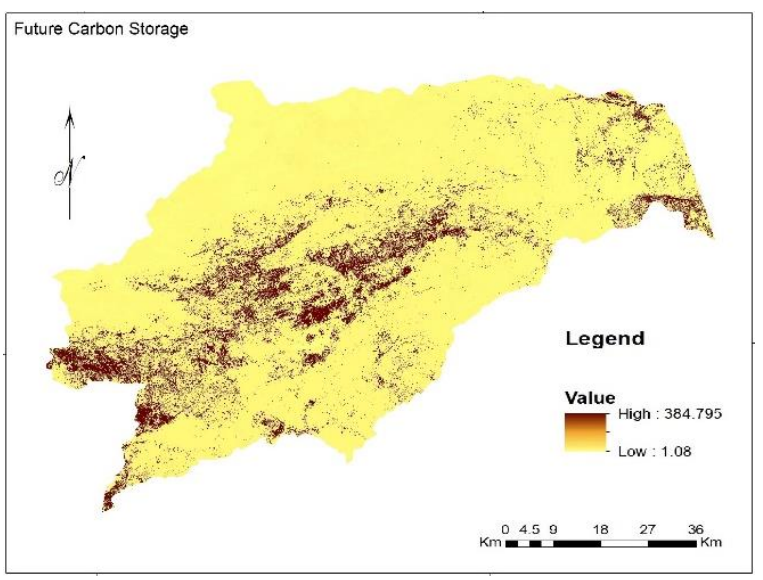

Figure 4: Two maps showing the currently stored carbon and the future projected carbon storage in $(\mathrm{mg} / \mathrm{pixel})$

The range of the future carbon storage ranges from $1 \mathrm{mg}$ to $384 \mathrm{mg}$ per pixel, which does not signify that much change given the time frame.

\subsection{Quantifying Crop Production}

Expanding agricultural production and closing yield gaps is a key strategy for development agencies focused on poverty alleviation and achieving food security (InVEST, 2018). However, the conversion of natural habitats to agricultural production impacts other ecosystem services that are key to sustaining the economic benefits that agriculture provides to local communities. Nonetheless, crop production is essential to human well-being and livelihoods (Russell et al, 2015; Maer et al, 2010; Li et al, 2016). Due to unavailability of data for Crop Production types in South Africa, a study was done by $(\mathrm{FAO}, 2005)$ on the fertilizer by crop, crop production. The data showed the rate of fertilizer that is used per different crop in the country.

\begin{tabular}{|l|l|l|l|}
\hline Crop & $\begin{array}{l}\text { Nitrogen } \\
(\mathrm{kg} / \mathrm{ha})\end{array}$ & $\begin{array}{l}\text { phosphorous } \\
(\mathrm{kg} / \mathrm{ha})\end{array}$ & $\begin{array}{l}\text { potassium } \\
(\mathrm{kg} / \mathrm{ha})\end{array}$ \\
\hline cotton & 36 & 22 & 3 \\
\hline maize & 55 & 30 & 6 \\
\hline sunflower & 15 & 21 & 2 \\
\hline potato & 170 & 160 & 120 \\
\hline soybeans & 7 & 25 & 8 \\
\hline sugarcane & 92 & 57 & 133 \\
\hline vegetables & 170 & 159 & 83 \\
\hline wheat & 30 & 40 & 4 \\
\hline citrus & 80 & 35 & 60 \\
\hline tobacco & 80 & 35 & 60 \\
\hline
\end{tabular}

Table 3: showing fertilizer rate per crop for some crops in South Africa, in ( $\mathrm{kg} / \mathrm{ha})$

The above table shows the rate of fertilizer as per chemical. This includes nitrogen, potassium and phosphorous. The results show that potatoes and horticultural vegetables use more fertilizer than other crops. Soybeans and cotton use the least of fertilizer in South Africa. The crops grown in Limpopo include field crop such as maize, industrial crops 
for example tobacco and horticulture and fruit crops (Figure $5)$.

\subsection{Regional Crop Production}

The assessments of the production of field crops in the different agricultural regions, described below, are approximate but more than 80 percent accurate (FAO, 2005). For example, both maize and wheat are grown in the dry subhumid region of Kwazulu-Natal, South Africa, but in the provincial context, the areas grown are small. The contributions of these "minor" regions, however, have been included in the total value of production and average national yields shown in Figure 5. Production yield and value of the crops planted in South Africa was extracted from www.FAO.org and it was populated in 2017.

The populated data shows the different crops and yield average as well as the production value. The data also shows crop production in area per thousand hectares. Within the South African context, maize, wheat, sunflower, and sugarcane are crops that are produced the most. Narrowed down to Limpopo, minor regions that produce these crops come at a subtotal of 2600 (000ha). Industrial crops are produced at a subtotal of 59 (000ha) annually. Horticulture crops and fruits are produced at $180000 \mathrm{ha}$ annually. This produces a total of 6514 (000ha) annually for crop production in South Africa, and since most of the crop production is done in Limpopo, a third of the total crop production is found there, (FAO, 2005). That means, 2171 (000ha) of crops is produced in Limpopo province, where the study area is located.

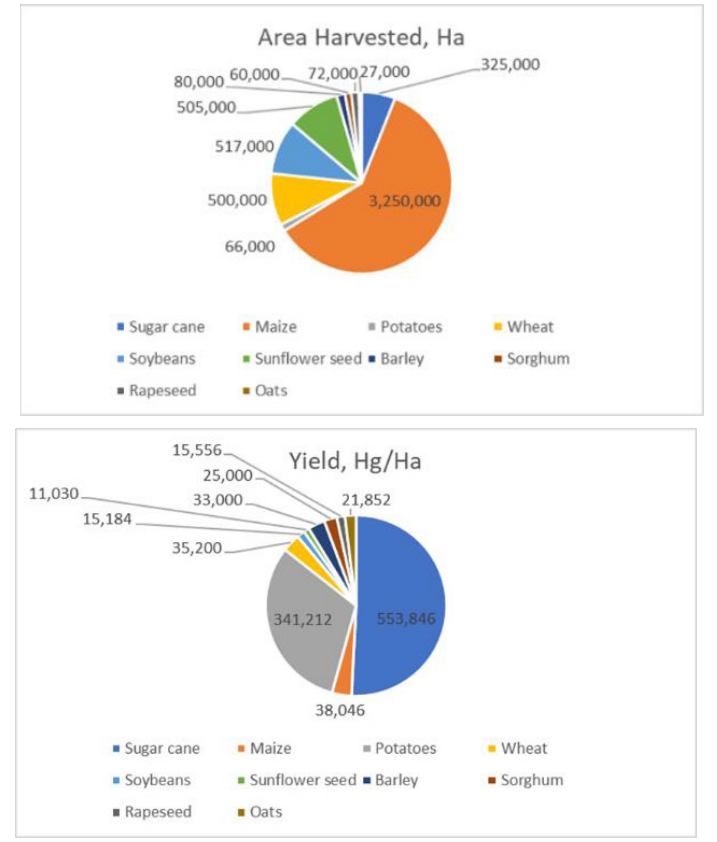

Figure 5: two pie charts showing crop (a) yield and (b) harvested in the study area in (Ha)

Figure 5 shows the crop production in 1000 tons. The graph Shows that in 2018, sugarcane was the most produced, at 18000 tons, maize was second at 13000 tons, potatoes were at 3000 tons and oats were the least produced at under 1000tons. Figure 5 also shows crop yield and crop harvested in 2018 from (FAO, 2018). Sugar cane was the most produced crop in 2018. Sunflowers were the least produced. Potatoes and maize were also produced in bulk in that year. While figure $5 b$ shows that maize was the most harvested crop in 2018 with sugarcane being the second harvested crop as well as sunflower and wheat.

\subsection{Scenario Based Tradeoffs}

In this section, correlations between carbon storage and different scenarios were made. The scenario-based model was used to calculate the changes in different scenarios. The proximity-based scenario generator creates a set of contrasting land use change maps that convert habitat in different spatial patterns (InVEST, 2018). The user determines which habitat can be converted and what they are converted to, as well as type of pattern, based on proximity to the edge of a focal habitat. In this manner, an array of landuse change patterns can be generated, including pasture encroaching into forest from the forest edge, agriculture expanding from currently cropped areas, forest fragmentation (InVEST, 2018). The resulting land-use maps can then be used as inputs to InVEST models, or other models for biodiversity or ecosystem services that are responsive to land use change. Two scenarios were modelled; bareland to cropland (BLTCL) and settlements to bareland (STLMTOBARE) using the most recent LULC map that is 2018. These scenarios were chosen solely based on the ability of these classes, to be converted by human induced activities and the recent date of the LULC map. The results show distance (in number of pixels) of the nearest edge to the focal cell/landcover.

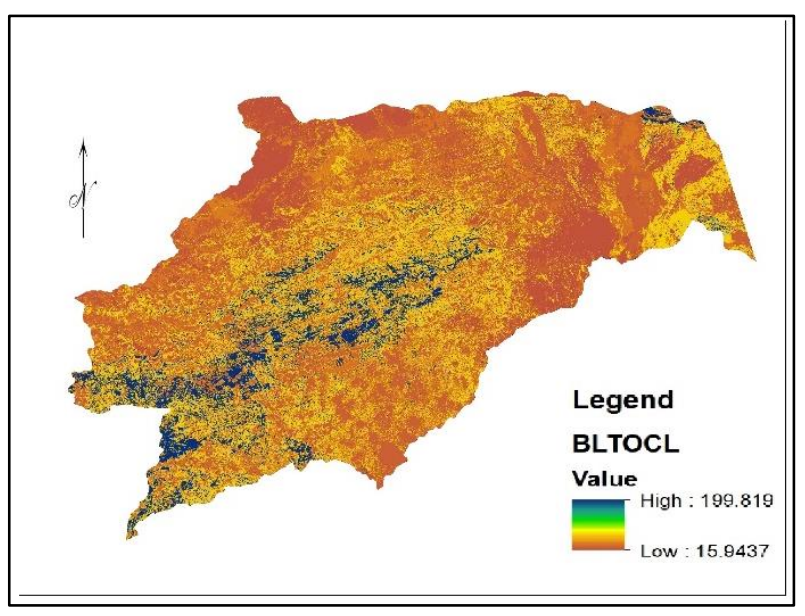

Figure 6: Map showing Bareland to Cropland (BRTCL) scenario in $\mathrm{mg} / \mathrm{pixel}$

Figure 6 shows a scenario that can affect agricultural practices within the study area. The ranges of the BRTCL are from $15 \mathrm{mg} /$ pixel to $118 \mathrm{mg} /$ pixels. While figure 7 shows a scenario that also has the potential to affect agricultural practices in the area. The ranges of STLMTOBARE is $14 \mathrm{mg} /$ pixel to $119 \mathrm{mg} /$ pixel. 


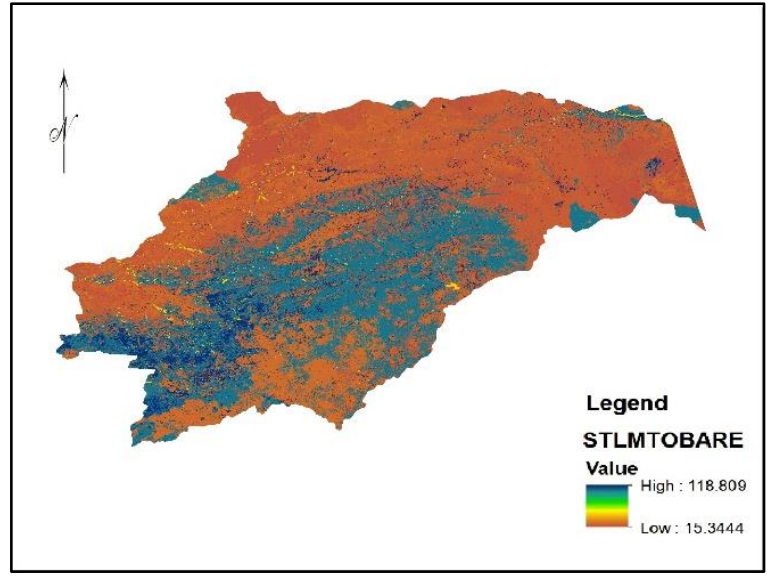

Figure 7: Map showing from Settlement to Bareland (STLMTOBARE) scenario in $\mathrm{mg} / \mathrm{pixel}$

\subsection{Spearman's Coefficient Correlation}

Spearman's rank correlation coefficient allows one to identify whether two variables relate in a monotonic function for example that when one number increases so does the other (Lautenbach et al, 2010). To calculate Spearman's rank correlation coefficient, one needs to rank and compare data sets to find $\Sigma \mathrm{d}^{2}$, then plug that value into the standard or simplified version of Spearman's rank correlation coefficient formula (Lautenbach et al, 2010).

$$
r_{k}=1-\frac{6 \Sigma d_{i}^{2}}{n\left(n^{2}-1\right)}
$$

where $\mathrm{n}$ is the number of data points of the two variables and di is the difference in the ranks of the ith element of each random variable considered. In this case, the random variable is the two datasets acquired from the LULC maps, (data1 and data2). The Spearman correlation coefficient, $\rho$, can take values from -1 to +1 . The closer $\rho$ is to -1 or +1 , the stronger the likely correlation. A perfect positive correlation is +1 and a perfect negative correlation is -1 .

\begin{tabular}{|l|l|l|l|l|l|l|}
\hline data1 & data2 & $\begin{array}{l}\text { rank } \\
\text { (dat1 }\end{array}$ & $\begin{array}{l}\text { rank( } \\
\text { dat2) }\end{array}$ & diff & $\begin{array}{l}\text { diff^ } \\
2\end{array}$ & \\
\hline 1.07 & 1 & 1 & 1 & 0 & 0 & \\
\hline 16.1 & 6 & 3 & 2 & 1 & 1 & \\
\hline 2.5 & 9 & 2 & 3 & -1 & 1 & \\
\hline 25 & 14 & 4 & 4 & 0 & 0 & \\
\hline & & & & sum & 2 & $\begin{array}{l}\text { sum(d } \\
\wedge\end{array}$ \\
\hline & & & & & 0.8 & \\
\hline
\end{tabular}

Table 4: Spearman's Autocorrelation. Data 1 and Data 2 is presented in $\mathrm{mg} / \mathrm{pixel}$

The overall coefficient was 0.8 which means the two maps were highly correlated.

\section{DISCUSSION AND CONCLUSION.}

The quantification and expression of ESS values and their trade-offs can predict environmental change and provide scientific backing for land use policies decisioning (Yang et al, 2018). The different research objectives covered in this study required different quantification and expression methods. Some studies demonstrated that trade-offs occur between regulating and provisioning services, while synergies are more likely to be generated by regulating services (Jia et al., 2014; Zheng et al., 2014; Lin et al., 2018). The results of this study arrived at the conclusion that tradeoffs indeed occur between these two services.

To begin, three objectives were set in this study, 1 . To map and quantify land cover change from 1999 to 2018,2 . to quantify carbon sequestration and crop production using (InVEST) and to assess current tradeoffs between provisional and regulating ESS in the study area. The results showed that the cropland class is the one that was growing at a constant rate from 1999 to 2018 . This can be attributed to the post-apartheid agricultural policies in South Africa that accommodated more farmers and farmlands within the country with time as well as the fact that most of the produce is exported out of the country for economic activities. When quantified, the croplands showed that most of the crops grown in the area is sugarcane and maize that contribute a significant amount of money to the country's GDP. The settlement class decreased from 1999 to 2018 . This may be due to the increased rural to urban migration that was experienced during the stipulated study period in South Africa. The study area is mostly rural, and coupled with urbanization, the population is bound to decrease.

The increase in the water in the study area from 1999 to 2008 may be due to the dam that was built to support people's livelihoods and to combat water scarcity issues within the catchment area. From 2008 to 2018, the water increase may be attributed to the spectral reflectance of the Landsat image upon computing an RGB composite for a random forest classification. This phenomenon causes the water in the RGB composite to appear brighter than other samples, leading to a misrepresentation in the algorithm for a perfect classification. I recommend that, a different set of satellites with a better spatial and spectral resolution be used in future studies. The user and producer accuracies for this class during the classification stage sat at $62 \%$ and $69 \%$ respectively. The decrease in vegetation may be attributed to the corresponding increase in bare land.

Carbon storage was computed through Invest Software and the results showed that the total current carbon storage stored in the study area is $569474851.61 \mathrm{mg} / \mathrm{pixel}$, Total future carbon stored is $620486641.59 \mathrm{mg} / \mathrm{pixel}$, the REDD scenario for carbon sits at $569474851.90 \mathrm{mg} / \mathrm{pixel}$ (figure 4). These results may be explained by the prevalence and abundance of cropland in the area. Interestingly, the presence of settlements contributed a small amount of the carbon as illustrated in the carbon maps. Therefore, the need to assess the tradeoffs between carbon and crop production was seen.

Due to the lack of spatial data on crop production in South Africa and the difficulty in attaining crop data from Southern Africa, a set of five studies were reviewed to quantify crop production. FAO (2018) provided a framework for the crop production in South Africa and the crop yield and harvest for the year 2018. The results showed that maize is the second most planted crop in Limpopo, but the most harvested. Sugarcane is the most planted crop in the country but the least harvested. This could be attributed to the food security issues in South Africa. Most of the sugarcane produced in 
the country is exported while the maize is used to feed the nation, (Van Langyelde, 2019).

The third objective set to quantify tradeoffs between the two ESS. This could not be achieved through spatial correlation due to the lack of spatial crop production data, however, a grading system was done through quantifying area covered by cropland and correlated it to the carbon pixel data. Using the Spearman's Coefficient Correlation, conceptual tradeoffs were calculated between the two ESS. The overall correlation value was 0.8 that shows a high correlation. This means that the two ESS have synergies and one affects the other. The limitations of this method are the fact that a spatial correlation was lacking as seen from the nature of the dataset.

The scenario-based tradeoff analysis is effective in a sense that different agricultural land use management policies and strategies or real-life situations can affect how land use planning is done. The two scenarios that were calculated were solely based on the human impacts on the ecosystem and the main drivers of the changes in the ESS. The two scenarios that were modeled were conceptual agricultural impacts that humans have on the ecosystem and these were from bare land to cropland and from settlements to bare land. The results showed an increase in changes of these two scenarios taking place in the study area and a corresponding increase in carbon storage. Although these scenarios were based on human induced change, Yang et al (2018) also notes that the model does not account for social changes or social responsibilities in any study area. From the perspective of sustainability, I also recommend that future scenario simulations should be guided by the UN SDGs framework.

This study conducted in the Nzhelele Catchment Area shows a corresponding increase in cropland to carbon storage. Thus, either the trade-off or synergistic relationships between ESS have strengthened. The bare land to cropland scenario exhibited both maximum overall ESS benefits and ESS trade-offs at the pixel level. Therefore, I suggest that more scenarios be modelled and more data to be collected, especially cropland data. Land use change scenario analyses can support land use planning and policy decisions. However, more extensive anthropogenic impacts such as climate change and the accumulation of organic pollutants were not reflected. Therefore, future studies should consider multiple interactions between social and natural systems to better evaluate and predict ESS. These studies will improve human well-being and enhance our ability to adapt to climate change in more comprehensive and credible ways.

\section{ACKNOWLEDGEMENTS}

This work was funded by The National Research Foundation, South Africa (Grant No 110778) and National Research Foundation, South Africa (Grant no. 119288)

\section{REFERENCES}

Alcamo, J., Van Vuuren, D., Cramer, W., Alder, J., Bennett, E., Carpenter, S., Christensen, V., Foley, J., Maerker, M., Masui, T. and Morita, T., 2016. Changes in ecosystem services and their drivers across the scenarios. Ecosystems and human well-being, 2, pp.297-373.
Apitz, S.E., Elliott, M., Fountain, M., Galloway, T.S., 2006. European environmental management, moving to an ecosystem approach. Integr. Environ. AssESS. Manage. 2 (1), 80-85.

Cai, W., Liu, C., Zhang, C., Ma, M., Rao, W., Li, W., He, K. and Gao, M., 2016. Developing the ecological compensation criterion of industrial solid waste based on emergy for sustainable development. Energy, 157, pp.940-948.

Chivian, E., Bernstein E. D., 2005. Sustaining Life. Oxford University PrESS. New York

De Groot, R.S., Wilson, M.A. and Boumans, R.M., 2002. A typology for the classification, description and valuation of ecosystem functions, goods and services. Ecological economics, 41(3), pp.393-408.

Dente, L.; Satalino, G.; Mattia, F.; Rinaldi, M. 2018. Assimilation of leaf area index derived from ASAR and MERIS data into CERES-Wheat model to map wheat yield. Remote Sens. of Environ. 2008, 112, 1395-1407.

Department of Agriculture and Forestry, 2016. South Africa.

Euliss Jr, N.H., Smith, L.M., Liu, S., Duffy, W.G., Faulkner, S.P., Gleason, R.A. and Eckles, S.D., 2011. Integrating estimates of ecosystem services from conservation programs and practices into models for decision makers. Ecological Applications, 21(sp1), pp.S128-S134.

Feng, X.M., Fu, B.J., Lu, N., Zeng, Y., Wu, B.F., 2013. How ecological restoration alters ecosystem services, an analysis of carbon sequestration in China's Loess Plateau. Sci.Rep. 3 (5), 2846

Food and Agriculture Organisation, 2005,2008,2015, 2018. http://www.fao.org/news/archive/news-by-date/2015/en/

Fu, B.J., Forsius, M., Liu, J., 2013. Ecosystem services: climate change and policy impacts. Curr. Opin. Environ. Sustain. 5 (1), 1-3.

Gockowski, J., Sonwa, D., 2011. Cocoa intensification scenarios and their predicted impact on $\mathrm{CO} 2$ emissions, biodiversity conservation, and rural livelihoods in the Guinea rain forest of West Africa. Environ. Manage. 48, 307-321.

Goldstein, J.H., Caldarone, G., Duarte, T.K., Ennaanay, D., Hannahs, N., Mendoza, G., Polasky, S., Wolny, S., Daily, G.C., 2012. Integrating ecosystem-service tradeoffs into land-use decisions. Proc. Natl. Acad. Sci. U. S. A. 109 (19), 7565-7570.

Hirsch, P., Van Thang, H., Trung, T.C., O'Connor, S., McShane, T., Brosius, P. and Norton, B., 2015. Eliciting inter-temporal value trade-offs: a deliberative multi-criteria analysis of Vietnam's Bai Tu Long National Park management scenarios. IAFOR Journal of Sustainability, Energy and the Environment, 2(1), pp.41-62.

Hou, Y., Li, B., Müller, F. and Chen, W., 2016. Ecosystem services of human-dominated watersheds and land use influences: a case study from the Dianchi Lake watershed in China. Environmental monitoring and assessment, 188(12), p.652. 
Hu, Y.N., Peng, J., Liu, Y.X., Tian, L., 2018. Integrating ecosystem services trade-offs with paddy land-to-dry land decisions, a scenario approach in Erhai Lake Basin, southwest China. Sci. Total Environ. 625, 849-860.

INVEST USER GUIDE, 2018, 2019
https://www.rain.co.za/offline/

Jia, K.; Wu, B.; Tian, Y.; Li, Q.; Du, X. 2014. An effective biophysical indicator for opium yield estimation. Computers and Electronics in Agriculture 2011, 75, 272-277.

Kareiva, P., Watts, S., McDonald, R. and Boucher, T., 2007. Domesticated nature: shaping landscapes and ecosystems for human welfare. Science, 316(5833), pp.1866-1869.

Kimmins JP, Mailly D, Seely B,. 2016. Modelling forest ecosystem net primary production: the hybrid simulation approach used in FORECAST. Ecol Model 122:195-224

King, E., Cavender-Bares, J., Balvanera, P., Mwampamba, T.H., Polasky, S., 2015. Trade-offs in ecosystem services and varying stakeholder preferences, evaluating conflicts, obstacles, and opportunities. Ecol. Soc. 20 (3), 25-39.

Lautenbach, S., van Delden, H., Newham, L.T. and Seppelt, R., 2010. How can we make progress with decision support systems in landscape and river basin management? Lessons learned from a comparative analysis of four different decision support systems. Environmental management, 46(6), pp.834-849.

Li, M., Wu, J. \& Deng, X. Reg Environ Change (2016) 16: 2429. https://doi.org/10.1007/s10113-016-0948-9

Lin, S.W., Wu, R.D., Yang, F.L., Wang, J.J., Wu, W., 2018. Spatial trade-offs and synergies among ecosystem services within a global biodiversity hotspot. Ecol. Indic. 84,371381 .

Makungo, R., Odiyo, J.O., Ndiritu, J.G. and Mwaka, B., 2010. Rainfall-runoff modelling approach for ungauged catchments: A case study of Nzhelele River sub-quaternary catchment. Physics and Chemistry of the Earth, Parts A/B/C, 35(13-14), pp.596-607.

Millennium Ecosystem AssESSment (MEA), 2005. Ecosystems and Human Well-being: Synthesis. Island PrESS, Washington, DC.

National Wildlife $\quad 2016$. https://www.nwf.org/natureguides?utm source=NWFdropd own\&utm medium $=$ web\&utm campaign $=$ GBTN\&utm co $\underline{\text { ntent }=03022020}$

Nelson, E., Mendoza, G., Regetz, J., Polasky, S., Tallis, H., Cameron, D., Chan, K.M., Daily, G.C., Goldstein, J., Kareiva, P.M., 2009. Modeling multiple ecosystem services, biodiversity conservation, commodity production, and tradeoffs at landscape scales. Front. Ecol. Environ. 7 (1), 4 11.

O'Farrell, P.J., Anderson, P.M., 2010. Sustainable multifunctional landscapes, a review to implementation. Curr. Opin. Environ. Sustain. 2 (1), 59-65.
Olver, C., 2012. Biodiversity loss and its impact on humanity. Nature 486 (7401), 59.

Polasky, S., Nelson, E., Pennington, D., Johnson, K.A., 2011. The impact of land-use change on ecosystem services, biodiversity and returns to landowners, a case study in the state of Minnesota. Environ. Resour. Econ. 48 (2), 219-242.

Raudsepphearne, C., Peterson, G.D., Bennett, E.M., 2010. Ecosystem service bundles for analyzing tradeoffs in diverse landscapes. Proc. Natl. Acad. Sci. U. S. A. 107 (11), 5242.

Seppelt, R., Lautenbach, S., Volk, M., 2013. Identifying trade-offs between ecosystem services, land use, and biodiversity, a plea for combining scenario analysis and optimization on different spatial scales. Curr. Opin. Environ. Sustain. 5 (5), 458-463.

Sharps, K., Masante, D., Thomas, A., Jackson, B., Redhead, J., May, L., Prosser, H., Cosby, B., Emmett, B. and Jones, L., 2017. Comparing strengths and weaknesses of three ecosystem services modelling tools in a diverse UK river catchment. Science of the total environment, 584, pp.118130 .

\section{South African Weather Services, 2018}

Styers, D.M., Chappelka, A.H., Marzen, L.J. and Somers, G.L., 2010. Developing a land-cover classification to select indicators of forest ecosystem health in a rapidly urbanizing landscape. Landscape and Urban Planning, 94(3-4), pp.158165 .

The National Wildlife Federation. (2016). Ecosystem Services. Environmental Protection Agency. New York.

van Langevelde, F., van de Vijver, C.A., Prins, H.H. and Groen, T.A., 2019. Effects of Grazing and Browsing on Tropical Savanna Vegetation. In The Ecology of Browsing and Grazing II (pp. 237-257). Springer, Cham.

Woomer, P.L., Touré, A., Sall, M., 2004. Carbon stocks in Senegal's Sahel transition zone. J. Arid Environ. 59, 499510

Yang, S., Zhao, W., Liu, Y., Wang, S., Wang, J. and Zhai, R., 2018. Influence of land use change on the ecosystem service trade-offs in the ecological restoration area: Dynamics and scenarios in the Yanhe watershed, China. Science of the total environment, 644, pp.556-566.

Yao, Y.; Liu, Q.; Liu, Q.; Li, X. LAI. 2019.retrieval and uncertainty evaluations for typical row-planted crops at different growth stages. Remote Sens. of Environ. 2008, 112, 94-106.

Zheng, Z.M., Fu, B.J., Feng, X.M., 2016. GIS-based analysis for hotspot identification of tradeoff between ecosystem services, a case study in Yanhe Basin, China. Chin.Geogr. Sci. 26 (4), 466-477.

Musakwa, W..;Wang, S..;Wei, F..;Malapane, O.L..;Thomas, M.M..;Mavengahama, S..;Zeng, H..;Wu, B..;Zhao, W..;Nyathi, N.A., et al., Survey of Community Livelihoods and Landscape Change along the Nzhelele and Levuvhu River Catchments in Limpopo Province, South Africa. Land, 2020. 9(3): p. 91. 